\title{
Love as an act of resistance: Ethical subversion in early childhood professional practice in England
}

Contemporary Issues in Early

Childhood

2021, Vol. 22(2) 124-139

(C) The Author(s) 2020

(c) (1)

Article reuse guidelines: sagepub.com/journals-permissions DOI: I0.1 I77/|463949|20932297 journals.sagepub.com/home/cie

@SAGE

\section{Lynette Morris (D)}

Middlesex University, UK

\begin{abstract}
Challenging the conventional binary of morality and subversion as opposing forces, this article presents a new construct of ethical subversion in early childhood education and care professional practice. The conceptual framework combines constructs of emotional labour and care ethics, and theorising on power and subversive tactics. Text generated from focus group discussions and individual semi-structured interviews with graduate early childhood education and care practitioners provides the concrete corpus for Foucauldian discourse analysis. Critical analysis elucidates how, on the one hand, practitioners working in England experience ethical boundaries reflecting dominant discourses, while, on the other, they feel morally committed to care responsively even if it contravenes rule-based ethics. Ethical subversion is born from both reason and emotion: these are acts of loving disobedience by experienced practitioners who possess a deep understanding of risk and the critical implications of their rule-bending. Ethical subversion is relational and individualistic, supporting a care pedagogy focusing on the individual care needs of young children. Conceptualisation of ethical subversion raises important issues in the areas of ethics, management and professionalism: ethical subversion is constructed as a powerful phenomenon, with potential for effecting positive transformation in the lives of children and their families, while simultaneously augmenting constructs of professionalism in early childhood education and care in England.
\end{abstract}

\section{Keywords}

care ethics, early childhood education and care, emotional labour, everyday tactics, Foucauldian discourse analysis, post-structuralism, professionalism

\section{Corresponding author:}

Lynette Morris, School of Health and Education, Middlesex University, Fenella Building, The Boroughs, London, NW4 4BT, UK.

Email: I.morris@mdx.ac.uk 


\section{Introduction}

This article demonstrates how certain forms of subversion enable early childhood education and care (ECEC) professionals to provide responsive care for the benefit of young children's learning and development. Critical analysis congruent with the philosophical ideologies of Foucault (2002) is employed to explore how power constrains, shapes and enables the behaviours of professionals working within ECEC in England, bringing theorising of ethical subversion in ECEC to public consciousness for the first time. A construct of responsible subversion has been long established in the nursing profession through the work of Hutchinson (1990); this form of rule-bending is characterised by experienced nurses carrying out small acts of kindness to make patients feel more comfortable, regardless of whether their actions contravene hospital policy (Collins, 2012). Rule-bending as acts of responsible subversion is justified by nurses as necessary in order to care for the patient responsively. The theorising of ethical subversion in ECEC builds on Hutchinson's (1990) conceptual work in hospitals. It would be exiguous to inquire into motivations for rule-bending within the caring professions without acknowledging how non-adherence to any policy could have potentially devastating consequences for all concerned. In addition to potential risks to the welfare of those cared for, there are serious professional, legal and emotional implications for staff and the organisation (Collins, 2012). In nursing, rule-bending is reported as more generally practised by the most experienced nurses, who are better positioned to evaluate risks (Husted et al., 2015). Rule-bending amongst nurses has been linked to a related construct of tolerance for rule-bending, which correlates with developing understanding of what constitutes real harm to patients (Collins, 2012). Similarly, a deep understanding of critical implications of rule-bending is presented here as a prerequisite for theorising slight violations of rules in ECEC as acts of ethical subversion.

The theorising and policy underpinning the enactment of a key person's duty within ECEC practice in England is central to contextualising ethical subversion. Since the publication of the Birth to Three Matters framework (Department for Education and Skills, 2002), practice guidance for ECEC settings in England has promoted a 'key person approach', underpinned by theory and scientific research advocating positive experiences of caregiver responsiveness within an attachment relationship (Bowlby, 1969) to encode infants' neural systems for cognition and emotional well-being (Gerhardt, 2014; Graham, 2008). Elfer et al. (2012: 18) define the key person approach as: 'A way of working in nurseries in which the whole focus and organisation is aimed at enabling and supporting close attachments between individual children and individual nursery staff'.

The Early Years Foundation Stage framework (Department for Children, Schools and Families, 2008) was introduced in England towards the end of 2007 and, since its implementation in 2008, the key person role has been promoted to the level of a statutory requirement from its previous guidance status. The Early Years Foundation Stage framework asserts that 'children learn to be strong and independent from a base of loving and secure relationships with parents and/or a key person' (Department for Children, Schools and Families, 2008: 5). Accordingly, forming and maintaining close emotional bonds with children became a statutory requirement of the ECEC practitioner's role. Alongside the key person imperative, there is also an expectation for acknowledgement of the uniqueness of each child, and for practitioners to respond to children's individual interests and needs (Department for Education, 2017). The United Kingdom (UK) government continues to legislate for emotional labour (Hochschild, 1983) and care ethics (Noddings, 1984) within 
ECEC; it is these two related constructs that contribute to the theoretical foundation for ethical subversion in ECEC professional practice in England.

\section{Theoretical framing of resistance as ethical pedagogy}

The conceptualisation of emotional labour, in Hochschild's 1983 germinal work titled The Managed Heart, has since been widely taken up in ECEC debates (see Colley, 2006; Taggart, 2011; Vincent and Braun, 2013). Parallels have been drawn between labouring in ECEC and the three types of labouring that Hochschild (1983) identified in caring roles: physical labour, mental labour and management of feelings as a requirement of the waged role - the latter being termed emotional labour. Although Hochschild's (1983) theoretical perspectives on the exploitation of emotions have informed a wide range of work over the last 30 years, her theoretical construct of feeling rules has been less well received and attracted criticism for not fully expressing the complexity of how emotions are utilised in the modern working world (Koch, 2013). It is apparent from Hochschild's (1983: 114) own reported data that the organisation is not the only agent in setting the emotional agenda: within a structure where anger is not a permitted emotion, a member of an airline cabin crew 'launders her anger, disguises it in mock courtesy and serves it up with flair' as she deliberately spills tomato juice over a complaining passenger dressed in a white suit. Hochschild's (1983) subjects are revealed to be simultaneously agentic and resistant through their creative subversion of behaviour rules (Götz, 2013). The notion that workers may act on different sets of feeling rules in response to the context and/or personal motivation diverges from Hochschild's (1983) original concept; similarly, a more complex understanding of employees' motivations within their emotional labouring informs the theorising of ethical subversion here.

Emotion rules form a part of the professional culture of some occupations. In the law, health and education sectors, they reflect 'an occupational ethos and specific morality' (Koch, 2013: 131). When an individual enters the caring professions, they make a moral commitment to care for others through kind, warm and gentle interactions (Colley, 2006). Their actions are ethical in the sense of being relational (Noddings, 1984). Their ethical care involves cognitive, emotional and action strategies set within a moral relationship between individuals (Tronto, 1993). Daily interaction with the same children and their families provides opportunities for ECEC practitioners to foster felt emotions and attachments which coordinate with the moral dimensions of their compassionate professionalism (Taggart, 2016). The wilful misdemeanour of Hochschild's (1983) airline cabin crew member, conducted under the guise of courteous service, is set within a very different context to that characterising emotional labour in the caring professions: relationships are longer term and foster sensitivity to the physical, psychological, cultural and spiritual needs of the cared for and their families (Vanlaere and Gastmans, 2011). Gilligan (1982), writing on feminist constructions within ethical dilemmas, expresses how morality is typically situated and emotional; morality is defined as 'a network of connection, a web of relationships that is sustained by a process of communication' (Gilligan, 1982: 29). Positioning actions as ethical in terms of being relational is critical to conceptualising ethical subversion in this article. An ethic of care involves the carer in a relationship with commitment, empathy, intuition, love and compassion (Sevenhuijsen, 1998). Caring by experienced ECEC professionals is ethical in terms that extend beyond collective approaches to providing protective supervision and care routines (Davis and Degotardi, 2015). The emotional 
work carried out by compassionate ECEC professionals constitutes care which is sensitive to the physical, psychological, cultural and spiritual needs of both the child and their family (Vanlaere and Gastmans, 2011).

Conceptualising care as ethical in terms of involving cognitive, emotional and action tactics set within a moral relationship between individuals (Tronto, 1993) posits working within an ethic of care as going beyond Hochschild's (1983) original definition of emotional labour. There is more complexity in how ECEC professionals enact emotional labour: the related mechanisms of prescriptive emotion management and philanthropic emotion management (Bolton and Boyd, 2003) may better reflect the enactment of emotional labour in ECEC, as they acknowledge responsiveness to the implicit meanings in social interactions. Employees may labour more strenuously in the performance of philanthropic emotion management, going beyond normal expectations if they have positive feelings for the others involved, or if they feel that there is something special about the situation. ECEC professionals labour at forming emotional bonds with individual children in order to provide relational care through affect attunement (Stern, 2000), even though long periods of sustaining emotionally close interactions with very young children place high emotional demands on the staff (Page and Elfer, 2013). Furthermore, the effort required in working closely with families and caring for toddlers and babies is not a constant; emotions may need to be managed far more strenuously in some situations than others. Consequently, emotional labour in ECEC is presented in this article as the dynamic enactment of care ethics, where understandings of care ethics support a care pedagogy to challenge formal boundaries of practice (Noddings, 1984).

Consideration of De Certeau's (1984) theorising on strategy and tactics is also useful in understanding how ECEC practitioners adapt their ways of working to best serve children and to protect the self under the conditions imposed on them. De Certeau (1984) theorises tactics as the everyday ways in which the subjugated reappropriate strategies used to exert control by the dominant within organisational power structures: the rules of the powerful are still applied, but in a way that is influenced by the less powerful, but never wholly determined by them. The rule prevails without change, adjustment or exception, while the situated tactics of the workforce manifest as everyday creative resistance.

\section{A personal approach to Foucauldian discourse analysis}

The ontological and epistemic stances adopted in this article reflect social constructivism, with the empirical study grounded in Foucauldian conceptualisations of discourse and power (Foucault, 2002) and critical analysis of discursive forms (Howarth, 2000). In accordance with Foucault's own dislike of prescription, my analytical approach is pragmatic. The methodological aim was to firmly fix my gaze on ideological positions, power relations and the practices derived from these, while avoiding the risk of being seduced by grammatical constructions at the expense of social and political implications (Hook, 2001). Text generated from focus group discussions and individual semi-structured interviews was analysed through repeated close reading, comparison and aggregation across data sets, and careful recording of analytical notes. The approach enabled identification of sets of ideas, or discourses, as a mediating lens through which to view outcomes of uneven power relationships in ECEC (see examples of the analysis in Table 1). 


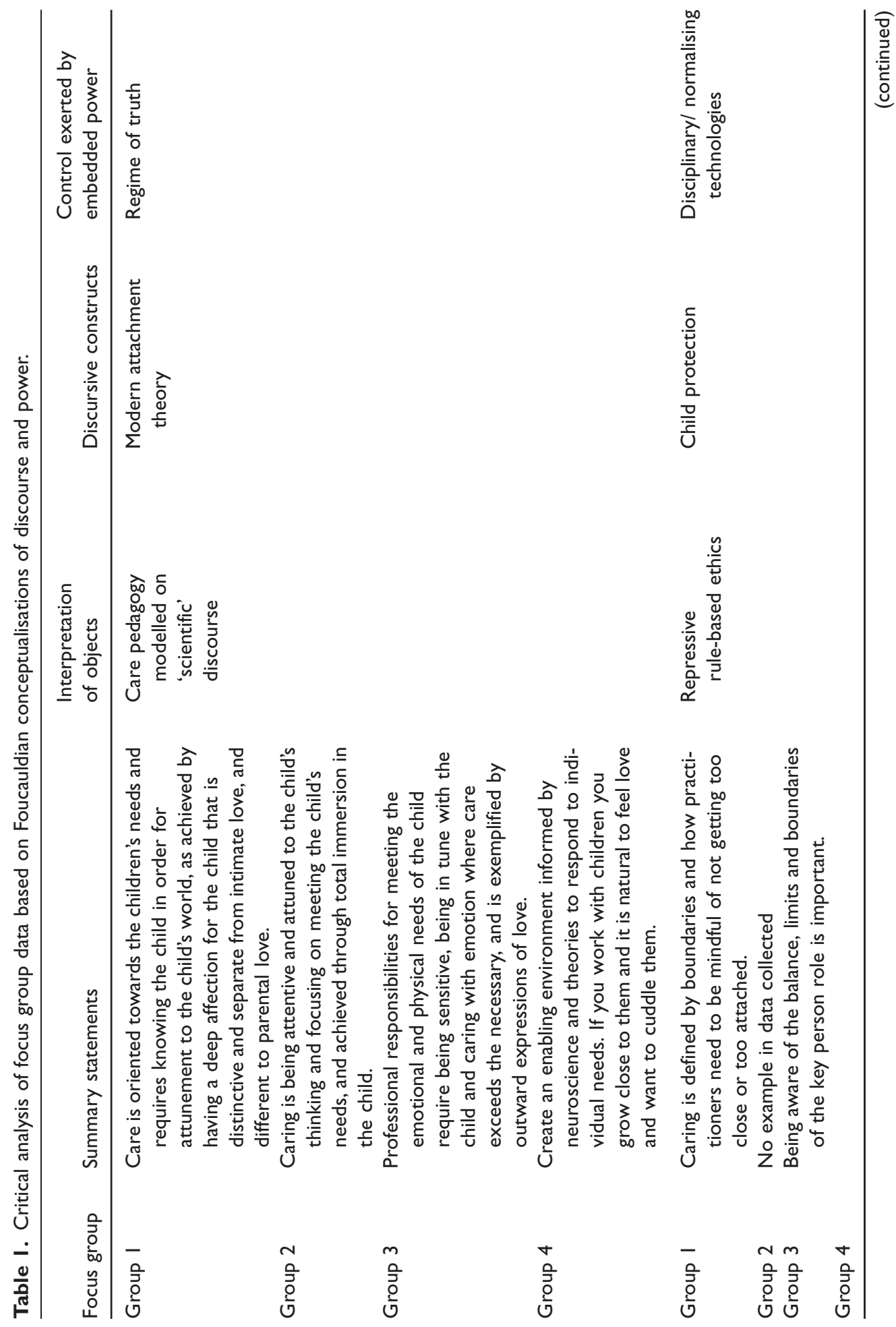




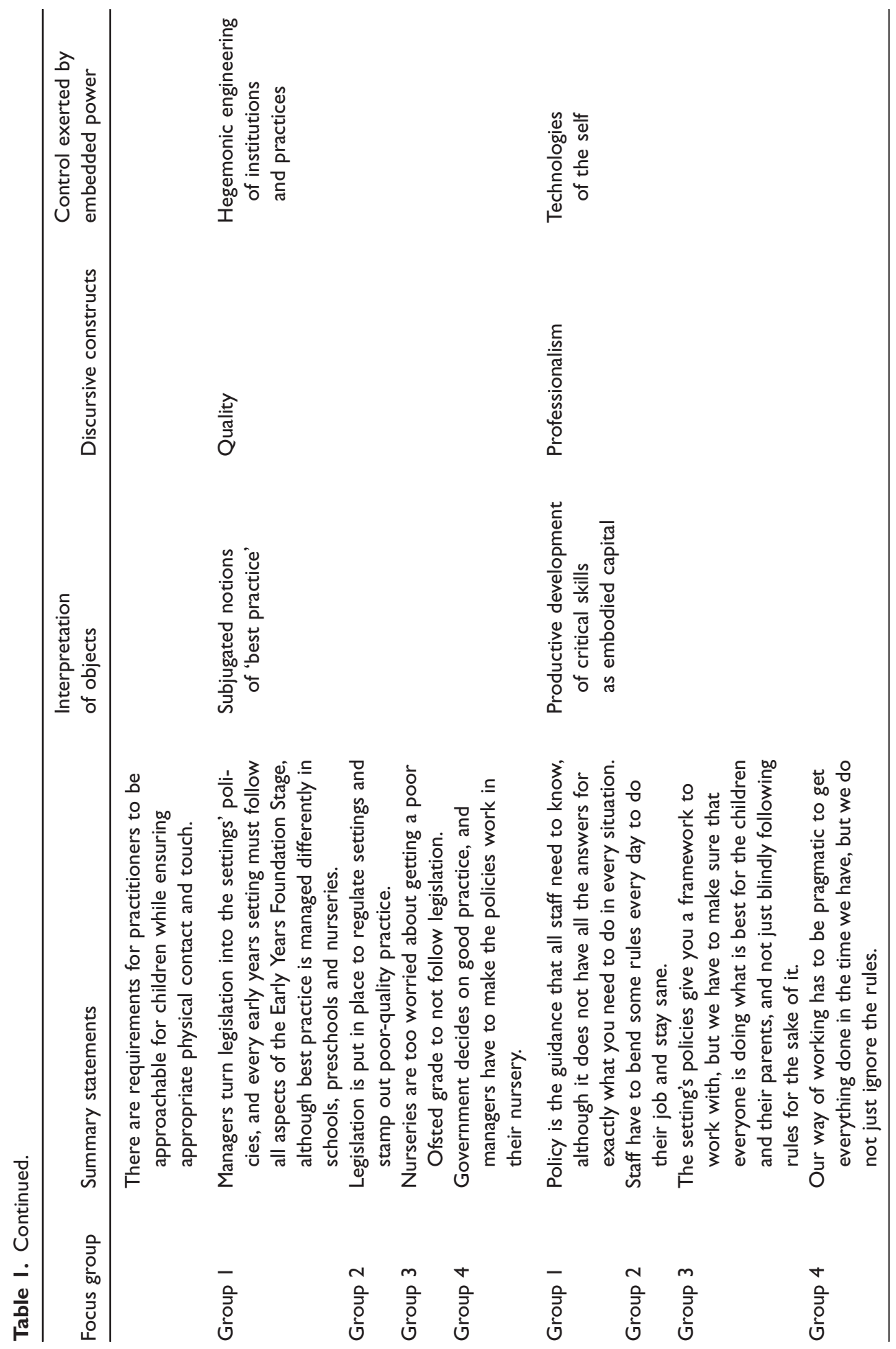




\section{Ethical gathering of examples of resistance}

The data was gathered at a university in North London, in the south-east of England, from a cohort of graduate ECEC practitioners in training towards the nationally recognised Early Years Teacher Status. The ECEC workforce in London is typically diverse, with the participant sample reflecting this position: the age range of the participants spans over 20 years and there is diversity in their cultural heritage, role, employment status, duration of experience in the ECEC sector, and experience of working with young children within and outside the UK. The use of four 5-member focus groups enabled 20 graduate practitioners to negotiate group perspectives through processes of expansion and reflection on each other's experiences (Belenky et al., 1997) to produce thick data summarising prevalent experiences, while three individual semi-structured interviews collected rich descriptions of personal experiences.

The participant recruitment, data collection and data handling were conducted in line with guidance published by the British Educational Research Association (2018). Ethical concerns relating to the data collection were rightly focused on care of the participants. Protective measures included the allocation of pseudonyms, participant debriefing and access to contact details for counselling. However, I had not fully appreciated the potential emotional impact of a deeply reflexive methodology on the practitioner researcher during the interview process. A state of sustained sensitive receptivity to nuances rendered me vulnerable to the psychoanalytic processes of projection and transference by a similar means to how practitioners experience children's intense emotions through their attunement to the child (see Elfer, 2016). Connections between the researcher and participants were deepened by the participants' openness and generosity in sharing their experiences. During the interviews with two of the participants, Anna and Maria, I found myself so deeply identifying with their retelling of upset and joy that it was palpable; unresolved emotions from years of working with children in difficult situations emerged and engulfed me. Furthermore, at one point in the interview with Maria, I sensed her pushing her feelings of despair, derived from her perceptions of the emotional sterility in school life, onto me. I also felt the redirection of Elena's annoyance with a 'weak' colleague; I became the object of Elena's impatience by probing rather than offering agreement to her interpretation as to why her colleague behaved as she did. I found myself to have been rendered vulnerable to the process of countertransference - the rise of my own strong negative feelings in response to Elena's criticism of her colleague's behaviours necessitated strenuous management of my own personal displays of emotion. I had not fully appreciated the inevitability of a redirecting of emotion onto the self, or how the retelling of the participants' experiences might rekindle emotions and unresolved internal struggles. I have come to understand how care of the practitioner researcher should be considered alongside concern for the care of the participants when engaging in practitioner research.

\section{Focus groups}

This subsection presents critical analysis of negotiated summary statements from the four focus group discussions, with the omissions assumed to provide no intimation of views or indifference. All four focus groups describe working within a care pedagogy which reflects a hegemonic attachment discourse. All four focus groups also describe the importance of ECEC settings adhering to national directives: Group 3 proffers a notion of the regulatory 
gaze of the Office for Standards in Education, Children's Services and Skills (Ofsted) in England exerting power through disciplinary technologies in imposing a dominant discourse of quality. Two groups also identify how the implementation of national policy in settings is open to management interpretation. For example, members of Group 4 refer to 'ensuring appropriate physical contact and touch', which in some settings has been interpreted as notouch policies. Over the years, both the benefits and dangers of 'touch' within educational and care contexts have been extensively debated (see Carlson, 2005; Johnson, 2000; Page and Elfer, 2013; Tobin, 1997). Fundamentally, policy relating to 'touch' is concerned with affording protection to children, their families, the staff and the ECEC setting. Furthermore, behaviour policies aiming to limit time spent in passive embrace positively support the premise that children require freedom to play, interact with other children and explore their environment. Long periods of being held on practitioners' laps, and frequent physical contact with carers, could potentially impede the development of a child's independence and learning (Dahlberg et al., 2007; Stern, 2000). However, close practitionerchild relationships in western ECEC are exemplified by outward expressions of love and affection, with Elfer et al. (2012: 62) encapsulating this position in the following statement: 'babies and young children need holding, cuddling and lap time, all of which are the very essence of being in a relationship'.

UK government guidance for schools acknowledges that it is both necessary and desirable for a teacher to have a degree of physical contact with a child, and advocates that schools should not impose a no-touch policy (Department for Education, 2011). Nevertheless, widely publicised incidents of child abuse over the last few decades have been described as having created confusion and a moral panic (Piper and Smith, 2003). A discourse of child protection has dominated in England, with close adult-child relationships coming under extreme levels of scrutiny (Page, 2017). UK legislation reflecting protection and control has been responded to as an overreaction to concerns for children's sexual safety and the false accusation of adults, with many ECEC settings discouraging staff displays of physical affection, such as cuddling or holding a child on a practitioner's lap. Consequently, within a context of fear and defensiveness, young children's fundamental needs may be ignored, and practice impoverished for both children and professionals (Piper and Smith, 2003). A discourse of child protection adds to the complexity of practitioners' close relationships with children (Campbell-Barr et al., 2015; Elfer et al., 2012; Page, 2017), supporting a more traditional rule-based ethics in ECEC settings.

Determination of the appropriateness of contact and touch is subjective, and subjected to tension between opposing external directives, competing discourses of what is best for children, and the differing internal beliefs of individual practitioners. All four focus groups recorded a broad consensus that practitioners work within their setting's policies while applying subversive tactics in order to fulfil or sustain their professional role. This position is reflected in Page's (2018: 137) observations of 'an informalisation of practice', whereby practitioners provide relational care 'outside of the official and formal framework of best practice'. While dominant discourses emphasise a requirement for loving care, protection from abuse and the nurture of independence, practitioners feel obliged to deploy subversive tactics to protect the self and balance the giving of too much physical affection with showing too little love. This position is further explored in the following three subsections. Brief profiles for three individual interviewees accompany critical discussion of their personal motivations for slight violations of behaviour rules under certain conditions. 


\section{Anna}

Anna is in her mid thirties and describes herself as an Italian who is resident in the UK. Anna has a long history of women teachers in her family; six years of her own ECEC employment were spent in Italian schools. At the time of interviewing, Anna explained that she was on unpaid placement in a large private nursery. Low staff recruitment and retention rates had resulted in a high percentage of agency staff working within all five rooms of the setting. In the excerpt below, Anna describes a scenario where, in the absence of the regulatory gaze of the room leader, she seizes the opportunity to encourage disenfranchised co-workers to join her in rule-bending:

I try several times when the room leader wasn't there because she is very strict and everyone, I said to them, 'Why don't we do this? Why don't we try this? Why don't we try to go outside and do this? Because in Italy it is much more happy and we go outside'. They were, like, 'How do you think we can do this?' And I thought, 'Oh my god'. This is a 50-year-old woman and a 22year-old woman. They just feel really anxious and spend their weekends looking for jobs.

Anna is describing how two other practitioners have been disempowered by working within uncompromising rules which act only to serve management's interests. A degree of autonomy is required to enable ECEC practitioners to use their professional expertise in linking purpose, context and how young children learn as ethical praxis. The strict rules on outdoor play marginalise other ways of knowing. Managerial repression has negated self-efficacy, rendering these practitioners unable to contemplate taking autonomous action (Bandura, 1982). Consequently, Anna is seen to encourage the other staff to deploy subversive tactics to enable them to better cope under the conditions imposed on them.

Anna expressed her enjoyment of working with babies and toddlers, describing her way of working as being akin to that of a caring mother. Mothering has been defined as the act of taking on responsibility for consistently responding to a child's universal demands for protection, nurture and socialisation, while maintaining an intense emotional connection (Ruddick, 1990). There may be blurred boundaries between many forms of professional caring and practitioners' experiences of personal caring, such as looking after vulnerable relatives. However, caring in ECEC practice has the potential to involve practitioners' feelings of love more directly than other forms of caring because of the direct relationship with parenting. In the interview excerpt below, it is apparent that Anna both cares for the children in her professional role and cares about them (Tronto, 1993). However, in this extract, Anna emphasises how her feelings of love are situated:

There is love, definitely. It's not just the same love. I love my friends, I love my husband, nephew to bits; my love for my nephew in Sardinia, because I don't see him. It's like a spectrum and it has different shades.

Anna asserts that she is emotionally bound to the children in her care. However, Anna also provides an honest admission that her feelings for the children she cares for in her work have a different quality to the feelings she has towards her friends and family. Gratzke (2015, cited in Page, 2018: 126) asserts that: 'Love is what people describe it as being'. This notion of love as having a multitude of definitions and representations aligns with Anna's framing of love as 'a spectrum'. There is a sense of hierarchy in the 
manifestations of Anna's love. When it comes to her feelings for the children in her workplace, her emotion is understandably less impassioned than for her family and friends. Furthermore, Anna does not display the same sense of longing as for her nephew. Admitting to not loving the children she cares for professionally as keenly as loving the individuals in her private relationships may feel uncomfortable in a professional context where there is emphasis on attachment. However, the distinction made by Anna demonstrates the self-awareness that is necessary for distinguishing between deploying emotion in 'healthy' practices and practices rendering children at risk of harm (Page, 2018).

The quality of Anna's private and professional love may be different. However, she is still positioned within a relationship with children who are the recipients of her affection. In the following extract, Anna describes a tension created by having deep affection for a child:

I think that boundaries can sometimes be crossed when [practitioners] are attached to the child, and I mean I have been in that situation myself with key children, and because we have such a good bond, you might not want to put certain rules in place, which becomes difficult ... keeping them on your lap, ermm, and letting them have things [fidgets with the hem of her clothing].

When Anna describes 'keeping' children on her lap to hold and cuddle, this may be in response to the child's care needs. However, it also satisfies her own emotional needs. Anna's admission to 'letting [children] have things' may be a tactic to encourage the children to like her and be compliant, while ignoring restrictions that do not present harm to children may also enhance feelings of happiness and pleasure in both Anna and the children. The way that Anna pauses, and makes small, restless movements with her hands as she speaks, suggests a degree of discomfort in admitting transgression from rules reflecting sector standards. The practitioner holds the perceived needs of the child, the practitioner and other children in dynamic tension, therefore Anna's discomfort may be interpreted as awareness of a potential for preferential treatment to stem from her love for some children. Anna's discomfort may signal fear of disciplinary action, resulting in loss of her placement in the setting, where threat of dismissal acts as a disciplinary technology. However, a more subtle reading of Anna's discomfort might suggest that her external restlessness is an outward manifestation of internal struggles relating to the subjectivity of what constitutes 'best for the child'. Anna, as an experienced carer of young children, would be expected to demonstrate acute awareness of the potential danger for practitioners to be guided by their internal moral compass, rather than by professional codes of practice. Nevertheless, there is evidence of tension between adhering to workplace rules and acting on situated practical knowledge of how to care for the child (Reinders, 2010).

\section{Elena}

Elena is in her early twenties and describes herself as a British Cypriot who has always lived, studied and worked in North London. Elena took up full-time permanent employment in a small 25-place private day nursery directly after completing a Bachelor's degree in Early Childhood Studies. She had been working in her current setting for six months at the time of interviewing, acting as the allocated key person for three infants. Elena describes her feelings for her key children as follows: 'I like them a lot but not in a kissy way'. The data collected during Elena's interview suggests little emphasis on physicality in her caring. She further explains that her key children 'settle quickly without [her] doing too much fussing over 
them'. Elena suggests an awareness of other practitioners showing more physical affection to the children. There is a sense that she is an outlier. Elena speaks of how one of her colleagues frequently picks up an infant, carrying the young child with her as she works around the setting, and regularly cuddling the child on her lap. Elena and other practitioners have different notions of best practice, which are guided by personal preferences and professional beliefs. Elena describes her setting's rules on physical displays of emotion by practitioners as an imperative for 'not spending too much time cuddling the children on their laps'. However, the subjectivity of what constitutes 'too much time' spent displaying physical affection gives rise to moral dilemmas, as children's needs are not a constant. ECEC professionals are put in the position of having to negotiate a fine line between when and to what extent to push ethical boundaries, demonstrating the intense moral demands of the caring situation.

Professional ECEC practice requires individuals to 'manage a caring self and emotionality "in the right way"” (Osgood, 2012: 113). New entrants into the UK's ECEC sector learn what constitutes professional behaviour while working in the setting. A setting's rules dictate which feelings are the appropriate emotions to express, and when and how to express them (Colley, 2006), and a discourse of professionalism becomes a disciplinary mechanism affirming appropriate work identities and conducts (Fournier, 2001). Elena describes her colleague's frequent physical displays of affection as 'unprofessional'; she tells the practitioner 'not to give in to [the child]', signalling a belief that these behaviours are signs of weakness and failure. However, it is not clear whether Elena is uncomfortable with her colleague's non-alignment with the practice that is deemed correct by authority or with not distinguishing between her professional role and that of a parent. Furthermore, Elena expresses annoyance that the child's parents encourage what she perceives as excessive displays of physical affection for a nonrelative child. In a western individualist culture, child-rearing is the private responsibility of the family, rather than the community: displays of affection for children are generally considered the private domain of relatives. Similarly, Elena's reactions to her colleague's physical displays of affection may demonstrate cultural tension in caring for non-relative children. Research has shown that ECEC practitioners in England may express anxieties about forming close individual relationships with the children in their care (Elfer, 2012; Page, 2011; Page and Elfer, 2013), particularly experiencing concerns over maintaining the correct degree of professional distance, and potential resentment from parents who worry that close relationships outside of the family could undermine home relationships. The differentials of power within relationships between ECEC practitioners and parents may affect practitioners' agency (Brooker, 2010). Consequently, a parent's preference for the practitioner to love their child (Page, 2011) may lead to the practitioner feeling obliged to display high levels of affection to fulfil the parent's wishes, even if it contravenes workplace rules and personal notions of the child's needs. However, without interviewing Elena's colleague directly, it is unknown whether she is experiencing internal difficulties in reconciling a felt discrepancy in her responsibilities to the parents, the child and the setting.

\section{Maria}

Maria is a self-employed childminder in her late forties. Maria has many years of professional experience in ECEC in both Venezuela and the UK. She worked as an assistant teacher in a public preschool in Venezuela for three years before qualifying as a preschool teacher; she then worked for a further four years as a preschool teacher before emigrating to the UK, where she continues to work as a self-employed childminder in North London. 
Maria speaks with pride about her skills as an ECEC professional, and describes her long career as a vocation:

Working with children, for me, I can do it standing on my head. I know it sounds like boasting but I had to find out what I was good at and I feel very privileged that I was able to find that I am good at [it].

Maria is an experienced ECEC professional with a strong sense of self-efficacy. Unlike Anna and Elena, Maria does not practise under the regulatory gaze of nursery management or colleagues. Her dominant position in the setting affords Maria more freedom to practise in ways which reflect her ideological position. Maria demonstrates conviction to her own professional judgments, experiencing ethical subversion as acts of political resistance. In the following extract, Maria redresses the differentials of power within practitioner-parent relationships while simultaneously invalidating a dominant sector no-hugging discourse:

For me, okay, ermm, it's just nice to have that little special link with a child. It's just really, I have this little girl who calls me 'Mama'. I know her mother isn't very happy but I feel just so warm and needed, and it just, it gives me pleasure in being able to satisfy that child's emotional needs [hugs her own body]. Just the children's joy, the happiness of the children, the smiles. I know it sounds really corny and too perfect, but it just makes my day when we play together and they give me a hug. Yeah, it is just fantastic. You have to wean them off because they have to go to school where no one is going to touch them, no one is even going to give them a little hug.

The practitioner-child attachment relationship provides benefits for both the one who is caring and the one who is cared for, regardless of a 'generous inequality' (Noddings, 1984: 67). Maria explains how receiving verbal and physical expressions of affection from a child makes her 'feel just so warm and needed'. Maria admits that her frequent demonstrations of physical affection contravene sector standards focusing on child protection in support of nurturing the child's emotional well-being. Maria explains that it gives [her] pleasure in being able to satisfy [a] child's emotional needs'. Maria expresses her concern for the children's emotional development in her explanation of how '[y]ou have to wean them off because they have to go to school where no one is going to touch them, no one is even going to give them a little hug'. Maria paints a picture of the school classroom as a site of emotional detachment. Her perception of schools as sterile and uncaring environments reflects an ECEC sector discourse of having the moral high ground on delivering care. It is not the regulatory gaze of managers, colleagues or parents which induces Maria's moderation of her physical contact with children in readiness for school; her actions are empathetic and indicate self-reflection and the capacity for self-regulation. Maria demonstrates use of the attachment relationship in a deliberate and purposeful way as she prepares children for transition to institutions where adult-child ratios are significantly lower, rendering a key person approach unfeasible. She concerns herself in the present with meeting the immediate emotional needs of each child by holding and cuddling, while simultaneously nurturing independence and resilience in response to their future needs. Maria's embodied care and pragmatic self-regulation are held in dynamic tension. For Maria, her subversive tactics are underpinned by her deep understanding of ethical praxis, and enacted as the deployment of critical skills at the sites of collision between her professional ideology in relation to meeting a young child's individual needs and incompatible hegemonic discourses 
of child protection, school readiness and schoolification. Maria's resistance is the enactment of her love and moral commitment to care responsively for each individual child.

\section{The subjectivity of ethics in ECEC professional practice}

The deconstruction of a traditional binary construct of morality and subversion is necessary in order to realise their 'mutually constituting and reproducing relation: rule-bending as a practical accomplishment' (Bloom and White, 2016: 7) - that is, the potentially positive function of subversion for upholding a broader set of ethical principles and achieving moral outcomes. Morality is subjective, and the subjective nature of ethical care intensifies the moral demands experienced by ECEC practitioners. Determination in support of ethical subversion is necessarily individualised and subjective. The cases included in this article present the decision-making of ECEC professionals working with very young children in London; the examples reflect a flexible and individualised approach to ECEC practice, and support the notion that emotional labour and care ethics are integral to sector professionalism in England (Taggart, 2016). The construct of ethical subversion presented here reflects a western individualistic society - more specifically, enactment of the key person's duty (Department for Children, Schools and Families, 2008). It is acknowledged that UK ECEC policy, which embraces relationship theory, is founded on a universal definition of love that is incompatible with other culturally contextualised models (White, 2016). Nevertheless, this policy is seen as central to contextualising ethical subversion within ECEC practice in England. The cases of subversive tactics presented in this article are ethical in terms of being relational; the rule-bending is set within a legislated practitioner-child attachment relationship where the ECEC professional labours for attunement to the individual needs of each child. Rule-bending and subversive tactics aligned to practitioners' beliefs of what is generally in the best interests of children are not theorised here as acts of ethical subversion, regardless of the sincerity of a practitioner's beliefs. Furthermore, it is acknowledged that any notions of heroism which may be mistakenly attached to acts of ethical subversion would reflect a particularly western discourse. Non-compliance with rulebased ethics would be unlikely to resonate with understandings of heroism and morality in more collective societies.

Experiencing ethics as subjective has a potentially positive function for ECEC practitioners and the sector more generally. While subjectivity may make staff feel more under pressure morally, the daily management of complex emotional relationships in ECEC practice leads to the development of critical skills as embodied capital (Bourdieu, 1986). This emotional capital enhances professional practice, enriches practitioners' enjoyment of the children, and promotes commitment to working in the sector (Andrew, 2015). ECEC practitioners are empowered by the 'potential opportunities to construct themselves as worthy, insightful, autonomous professionals' (Osgood, 2012: 14). Accordingly, theorising professionalism in ECEC practice in England as the deployment of critical skills to uphold a moral commitment to care values challenges a hegemonic discourse of professionalism as the attainment of higher qualifications and relaxation of statutory adult-child ratios.

\section{Conclusion}

The subject of rule-bending is knotty and emotive, and perhaps particularly so when applied to professional caring where the consequences of poor judgement could be devastating. It is 
not as simple as choosing which of the two camps to join - staunch supporters of the viewpoint that rules are there for a reason or advocates of the rules are there to be broken ideology. Social structures and practices within ECEC settings in England are subjected to ambiguity as the influence of national legislation aligned with relationship theories conflicts with hegemonic discourses of child protection, school readiness and schoolification. Furthermore, there are tensions between the key person approach and theories that emphasise children's need to be independent, and thinking that is suspicious of the western, middle-class, heteronormative assumptions about the self, families and attachment embedded in the policy.

The construct of ethical subversion builds on earlier theorising of emotional labour (Hochschild, 1983), care ethics (Noddings, 1984), tactics in everyday life (De Certeau, 1984) and responsible subversion in nursing (Hutchinson, 1990). Ethical subversion is born from both reason and emotion: these are acts of loving disobedience by experienced practitioners who possess a deep understanding of risk and the critical implications of their rule-bending. Ethical subversion is constructed as a powerful care pedagogy in ECEC settings in England. The subversive tactics constructed as ethical subversion are necessarily relational and individualistic, supporting a care pedagogy to challenge imperfect policy which conflicts with practitioner well-being and the individual care needs of young children. However, while the theorising of ethical subversion raises important issues in the area of ethics, management and professionalism in England, it is acknowledged that the legislative and cultural context is central to the construct, indicating that the phenomenon may not be experienced in the same way outside of England. Nevertheless, theorising ethical subversion demonstrates how subversive tactics can positively uphold a broader set of ethical principles when working with young children, while simultaneously augmenting constructs of professionalism in ECEC practice.

\section{Funding}

The author received no financial support for the research, authorship and/or publication of this article.

\section{ORCID iD}

Lynette Morris (D) https://orcid.org/0000-0003-0603-9048

\section{References}

Andrew Y (2015) 'I'm strong within myself': Gender, class and emotional capital in childcare. British Journal of Sociology of Education 36(5): 651-668.

Bandura A (1982) Self-efficacy mechanism in human agency. American Psychologist 37(2): 122-147.

Belenky MF, Clinchy BM, Goldberger MR and Tarule JM (1997) Women's Ways of Knowing: the development of self, voice, and mind. New York: Basic Books.

Bloom PN and White PJ (2016) The moral work of subversion. Human Relations 69(1): 5-31.

Bolton SC and Boyd C (2003) Trolley dolly or skilled emotion manager? Moving on from Hochschild's Managed Heart. Work, Employment and Society 17(2): 289-308.

Bourdieu P (1986) The forms of capital. In: Richardson J (ed.) Handbook of Theory and Research for the Sociology of Education. New York: Greenwood, pp. 241-258.

Bowlby J (1969) Attachment and Loss. London: Hogarth Press.

British Educational Research Association (2018) Ethical guidelines for educational research. Available at: http://www.bera.ac.uk/ 
Brooker L (2010) Constructing the triangle of care: Power and professionalism in practitioner/parent relationships. British Journal of Educational Studies 58(2): 181-196.

Campbell-Barr VJG, Georgeson J and Nagy Varga A (2015) Developing professional early childhood educators in England and Hungary: Where has all the love gone? European Education 47(4): 311-330.

Carlson FM (2005) Significance of touch in young children's lives. Young Children 6(4): 79-85.

Colley H (2006) Learning to labour with feeling: Class, gender and emotion in childcare education and training. Contemporary Issues in Early Childhood 7(1): 15-29.

Collins SE (2012) Rule-bending by nurses: Environmental and personal drivers. Journal of Nursing Law 15(1): 14-23.

Dahlberg G, Moss P and Pence A (2007) Beyond Quality in Early Childhood Education and Care: Postmodern Perspectives. 2nd ed. London: Falmer Press.

Davis B and Degotardi S (2015) Who cares? Infant educators' responses to professional discourses of care. Early Child Development and Care 185(11-12): 1733-1747.

De Certeau M (1984) The Practice of Everyday Life. Oakland, CA: University of California Press.

Department for Children, Schools and Families (2008) Practice Guidance for the Early Years Foundation Stage. London: Department for Children, Schools and Families.

Department for Education (2011) School discipline: new guidance for teachers. Available at: https:// www.gov.uk/government/news/school-discipline-new-guidance-for-teachers

Department for Education (2017) Statutory framework for the early years foundation stage: Setting the standards for learning, development and care for children from birth to five. Available at: https://www.gov.uk/government/uploads/system/uploads/attachment_data/file/596629/EYFS_

STATUTORY_FRAMEWORK_2017.pdf

Department for Education and Skills (2002) Birth to Three Matters. London: Department for Education and Skills.

Elfer P (2012) Emotion in nursery work: Work discussion as a model of critical professional reflection. Early Years 32(2): 129-141.

Elfer P (2016) Psychoanalytic theory, emotion and early years practice. In: David T, Goouch K and Powell S (eds) The Routledge International Handbook of Philosophies and Theories of Early Childhood Education and Care. Abingdon: Routledge, pp. 69-79.

Elfer P, Goldschmied E and Selleck D (2012) Key Persons in the Nursery. 2nd ed. London: David Fulton. Foucault M (2002) The Archaeology of Knowledge. Abingdon: Routledge.

Fournier V (2001) The appeal to 'professionalism' as a disciplinary mechanism. Sociological Review 47(2): $280-307$.

Gerhardt S (2014) Why Love Matters: How Affection Shapes a Baby's Brain. 2nd ed. London: Routledge.

Gilligan C (1982) In a Different Voice: Psychological Theory and Women's Development. Cambridge, MA: Harvard University Press.

Götz I (2013) Encountering Arlie Hochschild's concept of 'emotional labor' in gendered work cultures: Ethnographic approaches in the sociology of emotions and in European ethnology. In: Koch G and Buchanan SE (eds) Pathways to Empathy: New Studies on Commodification, Emotional Labor, and Time Binds. Frankfurt: Campus, pp. 183-200.

Graham L (2008) The neuroscience of attachment. Available at: http://lindagraham-mft.net/resources/ published-articles/the-neuroscience-of-attachment

Hochschild A (1983) The Managed Heart: Commercialization of Human Feeling. Berkeley, CA: University of California Press.

Hook D (2001) Discourse, knowledge, materiality, history: Foucault and discourse analysis. Theory and Psychology 11(4): 521-547.

Howarth D (2000) Discourse. Maidenhead: Open University Press.

Husted GL, Scotto CJ, Wolf KM, et al. (2015) Bioethical Decision-Making in Nursing. 5th ed. New York: Springer. 
Hutchinson SA (1990) Responsible subversion: A study of rule-bending among nurses. Research and Theory for Nursing Practice 4(1): 3-17.

Johnson RT (2000) Hands Off! The Disappearance of Touch in the Care of Children. New York: Peter Lang.

Koch G (2013) Feeling rules: Unfound treasures for the study of work cultures. In: Koch G and Buchanan SE (eds) Pathways to Empathy: New Studies on Commodification, Emotional Labor, and Time Binds. Frankfurt: Campus, pp. 123-140.

Noddings N (1984) Caring: A Feminine Approach to Ethics and Moral Education. Berkeley, CA: University of California Press.

Osgood J (2012) Narratives from the Nursery: Negotiating Professional Identities in Early Childhood. London: Routledge.

Page J (2011) Do mothers want professional carers to love their babies? Journal of Early Childhood Research 9(3): 310-323.

Page J (2017) Educators' perspectives on attachment and professional love in early years settings in England. In: White E and Dalli C (eds) Under-Three Year Olds in Policy and Practice. Singapore: Springer, pp. 131-142.

Page $\mathbf{J}$ (2018) Characterising the principles of professional love in early childhood care and education. International Journal of Early Years Education 26(2): 125-141.

Page J and Elfer P (2013) The emotional complexity of attachment interactions in nursery. European Early Childhood Education Research Journal 21(4): 553-567.

Piper H and Smith H (2003) Touch in educational and child care settings: Dilemmas and responses. British Educational Research Journal 29(6): 879-894.

Reinders H (2010) The importance of tacit knowledge in practices of care. Journal of Intellectual Disability Research 54(1): 28-37.

Ruddick S (1990) Maternal Thinking: Towards a Politics of Peace. London: Women's Press.

Sevenhuijsen S (1998) Citizenship and the Ethics of Care: Feminist Considerations on Justice, Morality, and Politics. Abingdon: Routledge.

Stern DN (2000) The Interpersonal World of the Infant. New York: Basic Books.

Taggart G (2011) Don't we care? The ethics and emotional labour of early years professionalism. Early Years 31(1): 85-95.

Taggart G (2016) Compassionate pedagogy: The ethics of care in early childhood professionalism. European Early Childhood Education Research Journal 24(2): 173-185.

Tobin J (1997) Making a Place for Pleasure in Early Childhood Education. New Haven, CT: Yale University Press.

Tronto J (1993) Moral Boundaries: A Political Argument for an Ethic of Care. New York: Routledge. Vanlaere L and Gastmans C (2011) A personalistic approach to care ethics. Nursing Ethics 18(2): 161-173.

Vincent C and Braun A (2013) Being 'fun' at work: Emotional labour, class, gender and childcare. British Educational Research Journal 39(4): 751-768.

White EJ (2016) Introducing Dialogic Pedagogy: Provocations for the Early Years. London: Routledge.

\section{Author biography}

Lynette Morrisis a senior lecturer in Education Studies and Early Childhood at Middlesex University London, where she teaches infant health and wellbeing, special educational needs and disability, early years professional practice, and national and alternative curricula in schools. Her research focus, including her completed doctoral study, explores the affective dimension of teaching and caring for young children. 